\title{
Research Progress in Toughening Modification of Polybenzoxazine
}

\author{
Sipei Zhao, Li Pei, Hailong Li, Yuanyuan Ma, Qingsong Lian, Shaofeng Zhou, Guizhe Zhao and Zhi Wang*
}

\begin{abstract}
Benzoxazine is a new kind of phenolic resin developed in recent years. It possesses a lot of interesting properties including flexible molecular design, nearly zero curing shrinkage and corresponding polybenzoxazine shows excellent mechanical and heat resistance properties. However, like other thermosetting resins, polybenzoxazine also faces the disadvantages of high brittleness and low impact strength during use. This paper briefly summaries the research progress of the toughening modification of polybenzoxazine, including rubber elastomer, inorganic particles, thermoplastic engineering plastic, other thermosetting resin, hyperbranched polymer and benzoxazine molecular design modification. Furthermore, the development direction of the toughening modification of polybenzoxazine has prospected.
\end{abstract}

Keywords: Polybenzoxazine; Toughness modification; Thermoset resin; Mechanical properties, Microstructure.

Received: 11 September 2020; Accepted: 30 October 2020.

Article type: Review article.

\section{Introduction}

Polybenzoxazine has gained a lot of attention in electronic packaging, the aerospace industry, composite fabricating, coatings and other fields ${ }^{[1-6]}$ because of its attractive properties, including excellent mechanical properties, heat resistance, flame retardancy, dimensional stability, low water absorption and low dielectric constant. ${ }^{[7-11]}$ However, polybenzoxazine is also faced with the disadvantage of brittleness, ${ }^{[12]}$ which greatly limits its application in aerospace and other high-tech fields such as high-performance structural areas. Therefore, the research on the toughening modification of polybenzoxazine is of great significance.

In this article, the research progress and mechanism of the toughening modification of polybenzoxazine are reviewed, which not only has theoretical significance for the toughening of thermosetting resin but also has obvious practical significance for expanding the application scope of benzoxazine resin.

\section{Toughening mechanism of polybenzoxazine}

Benzoxazine is a benzo six-membered heterocyclic compound synthesized from phenols, primary amines and aldehydes as

Research Center for Engineering Technology of Polymeric

Composites of Shanxi Province, School of Materials Science and

Engineering, North University of China, Taiyuan, 030051, China

*Email: shikouri@163.com (Z.Wang) shown in Scheme 1. Benzoxazine can be polymerized without byproducts by no using strong acid or basic catalysts (Scheme $2){ }^{[13,14]}$ The superior properties of polybenzoxazine mainly come from the Mannich base bridge $\left(-\mathrm{CH}_{2}-\mathrm{N}(\mathrm{R})-\mathrm{CH}_{2}-\right)$ and the hydrogen bonds between the phenolic hydroxyl group and the amine group (intramolecular and intermolecular). ${ }^{[15]}$ However, according to previous reports, $-\mathrm{OH} \cdots \mathrm{N}$ hydrogen bonds of polybenzoxazine decrease the charge densities of the corresponding phenolic hydroxyl group, thereby preventing the high-degree polymerization and resulting in a low crosslink density, which is the key issue that hinders the mechanical properties, including the toughness properties. ${ }^{[16]}$

To improve the toughness of polybenzoxazine, two methods have been demonstrated in recent researches. One method of toughening is to achieve a balance between toughness and rigidity by copolymerizing or blending two or more different materials to form a two-phase or multiphase structure. The key of this toughening method is to control the phase structure of the cured composite. One controlling method is directly adding the second discontinuous toughening phase, which consists of small particles with certain morphology and size dispersed in the prepolymer, such as rubber particles, inorganic nanoparticles. ${ }^{[17-19]}$ Toughening can be achieved by this method through the prevention of crack growth by particles and changing the direction of crack growth. The other form is using a toughening agent which is soluble in the benzoxazine resin. As the crosslink degree of the resin increases during the curing process, the compatibility 


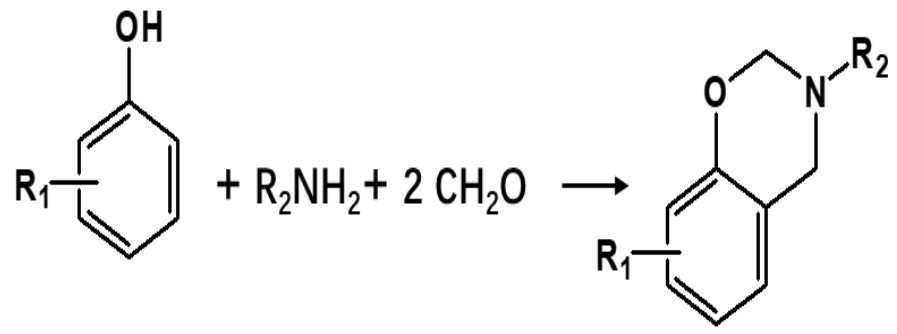

Scheme 1. Synthesis and structure of typical benzoxazine.

between the toughening agent and the resin deteriorates thereby the reaction induces phase separation occurs. This method is usually shown for the toughening of benzoxazine resin by thermoplastic resins and other thermosetting resins. ${ }^{[20-}$ 22] Sea-island structure, bi-continuous phase structure and phase inversion structure can be formed and can effectively improve the toughness properties of the system. ${ }^{[22]}$

The other method is to synthesize a new structure of benzoxazine through molecular design. Benzoxazine monomer is synthesized by a Mannich reaction from phenol, paraformaldehyde and primary amine (Scheme 1) which provides remarkable molecular design flexibility. By changing the phenol and amine source, reactive flexible groups can be introduced into the monomer, thereby increasing the crosslink density and improving the toughness of the cured product can be realized. The designed and synthesized benzoxazine monomer can also be added to the conventional resin with high crosslink density for modification, which acts as a toughening agent or diluent. On the other hand, design and synthesize benzoxazine group terminated molecules can also be used for improving the toughness or for modification of other kinds of thermoset resins. These benzoxazines can be divided into four categories according to their molecular structures: (1) small molecule benzoxazines, ${ }^{[15,23,24]}$ (2) main chain benzoxazines, ${ }^{[25-29]}$ (3) side chain benzoxazines, ${ }^{[30,31]}$ (4) telechelic benzoxazine. ${ }^{[32-34]}$<smiles>[R][X]1=CC=CC2=CN([R2])COC1=C2</smiles>
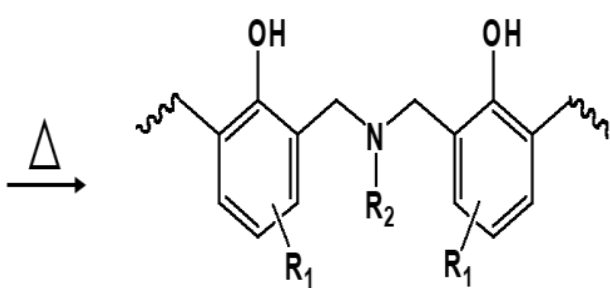

Scheme 2. Curing process of typical benzoxazine.

\section{Toughening modification of polybenzoxazine} 3.1 Directly adding the second discontinuous toughening phase

\subsubsection{Rubber modified polybenzoxazine}

Blending with elastomers such as rubber is a useful method for toughening thermosetting resins. During curing, the rubber segment can generally be precipitated from the matrix and form a two-phase structure, in which the rubber is dispersed in the continuous phase of the thermosetting resin as spherical particles. When the system is subjected to external impact, the two-phase interface plastically deforms due to the presence of rubber particles. The micro-cracks are generated at the interface and consume external force to prevent the extension of the cracks, to achieve the purpose of toughening. ${ }^{[35]}$ Reactive liquid rubbers, such as epoxy terminated nitrile rubber $(\mathrm{ETBN}),{ }^{[36]}$ amino terminated nitrile rubber $(\mathrm{ATBN}),{ }^{[17,37]}$ vinyl terminated nitrile rubber $(\mathrm{VTBN}),{ }^{[38]}$ hydroxyl terminated nitrile rubber (HTBN), ${ }^{[39]}$ carboxyl terminated nitrile rubber $(\mathrm{CTBN})^{[40]}$ (Scheme 3, Table 1), have attracted much attention due to their high elasticity and selective reactive end groups.

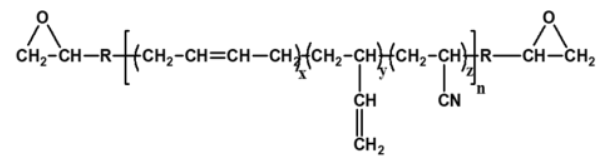

ETBN

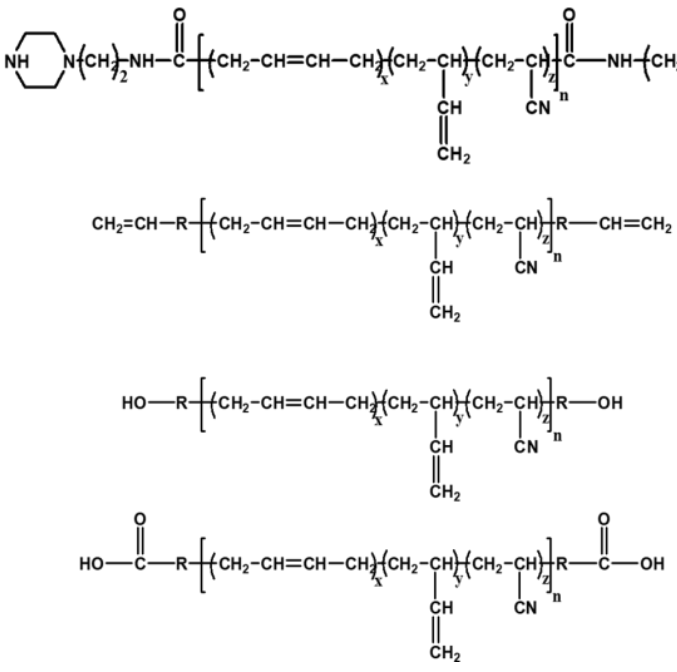

ATBN

VTBN

HTBN

CTBN

Scheme 3. Chemical structures of ETBN, ATBN, VTBN, HTBN and ETBN.

Grishchuk et al. ${ }^{[36]}$ used ETBN as a modifier to strengthen the benzoxazine/epoxy (BOZ/EP) blend system. ETBN formed water drop like island structure with a micrometer scale in the BOZ/EP network. The fracture toughness and fracture energy of the blends increases from $0.69 \pm 0.04$ $\mathrm{MPa} \cdot \mathrm{m}^{1 / 2}, 213 \pm 21 \mathrm{~J} \cdot \mathrm{m}^{2}(\mathrm{EP} / \mathrm{BOZ}=50 / 50)$ to $0.92 \pm 0.02$ $\mathrm{MPa} \cdot \mathrm{m}^{1 / 2}, 470 \pm 36 \mathrm{~J} \cdot \mathrm{m}^{2}(\mathrm{EP} / \mathrm{BOZ} / \mathrm{ETBN}=40 / 40 / 20)$, but due to the addition of ETBN, char yield, fire resistance, flexural modulus, flexural strength and $\mathrm{T}_{\mathrm{g}}$ of the system all have deteriorated. Suwitanningsih et al. ${ }^{[40]}$ further toughened bisphenol F-aniline polybenzoxazine (PF-a) by using ATBN, CTBN and ETBN. The effect of different reactive end groups on the structure and properties of the blends were also investigated. The results show that ATBN is the best toughening modifier due to the acid base interaction between the phenolic groups of polybenzoxazine and the amino terminal groups of ATBN, which form a better homogeneity between ATBN and polybenzoxazine. Furthermore, the surface of ATBN/PF-a composite keeps uniform and smooth with the increase of modifier content, while the voids and 
Table 1. Details of rubber modified polybenzoxazine.

\begin{tabular}{|c|c|c|c|c|c|}
\hline Modifier & $\begin{array}{c}\text { Tensile strength } \\
(\mathrm{MPa})\end{array}$ & Elongation at break & $\begin{array}{c}\text { Impact strength } \\
\left(\mathrm{kJ} \cdot \mathrm{m}^{-2}\right)\end{array}$ & $\mathrm{T}_{\mathrm{g}}\left({ }^{\circ} \mathrm{C}\right)$ & Ref. \\
\hline $\begin{array}{c}\text { ATBN } \\
(5 \mathrm{wt} \%)\end{array}$ & $\begin{array}{c}21.2 \% \uparrow \\
(50.5 \text { to } 61.2)\end{array}$ & $1.6 \%$ to $2.2 \%$ & l & $\begin{array}{c}13{ }^{\circ} \mathrm{C} \uparrow \\
\text { (205 to } 218)\end{array}$ & {$[40]$} \\
\hline $\begin{array}{c}\text { CSR } \\
(32 \mathrm{wt} \%)\end{array}$ & $\begin{array}{c}127 \% \uparrow \\
(24.7 \text { to } 20.5)\end{array}$ & $7.9 \%$ to $34.1 \%$ & l & $\begin{array}{c}6{ }^{\circ} \mathrm{C} \uparrow \\
\text { (191 to } 197)\end{array}$ & {$[41]$} \\
\hline $\begin{array}{l}\text { UFXNBR } \\
(250 \mathrm{kGy})\end{array}$ & l & l & $\begin{array}{c}108 \% \uparrow \\
\text { (7.2 to } 15)\end{array}$ & $\begin{array}{c}8^{\circ} \mathrm{C} \uparrow \\
(165 \text { to } 173)\end{array}$ & {$[42]$} \\
\hline
\end{tabular}

/ represents the performance is not tested in the reference.

bubbles appear on the surface of CTBN/PF-a composite due to the esterification reaction between the CTBN terminal carboxyl group and the phenolic hydroxyl group generated by the ring opening of benzoxazine. When the content of ATBN reaches $5 \mathrm{wt} \%$, the tensile strength of ATBN/PF-a increases from 50.5 MPa for pristine PF-a to $61.2 \mathrm{MPa}$ for blends, and the elongation at break increases from $1.6 \%$ to $2.2 \%$. Meanwhile, the addition of ATBN increases the system crosslink density and leads to the improved thermal stability of benzoxazine. Most liquid rubbers can effectively improve toughness with the deterioration of strength, modulus and thermal stability of final products because of the low strength and modulus of the liquid rubber elastomer itself. ${ }^{[17,36,40]}$

Core-shell rubber (CSR) is also used for toughening thermosetting resin. The soft core provides toughness for the composite, and the hard shell with good compatibility with the matrix resin provides extra strength. By blending CSR with benzoxazine, the strength and toughness of the resin can be effectively improved simultaneously. Douse et al..$^{[4]]}$ used CSR with siloxane as a core and acrylic acid as a shell to modify benzoxazine. When the CSR concentration increases to 32 $\mathrm{wt} \%$, the average elongations of the system increase from 0.82 $\mathrm{mm}$ for pure poly (BA-a) to $1.14 \mathrm{~mm}$ for blends, meanwhile modest improvement in $\mathrm{T}_{\mathrm{g}}\left(6^{\circ} \mathrm{C}\right)$ and significant enhancement of thermal stability $(20 \%)$ are achieved. But soft elastomeric particles still deteriorate the stiffness of poly (BA-a). The Young's modulus of the final product decreases from $5.4 \mathrm{GPa}$ for poly (BA-a) to $3.1 \mathrm{GPa}$ for blends.

In recent literature, ${ }^{[42]}$ three types of ultrafine fully vulcanized powdered rubbers (UFRs), including natural rubber (NR), carboxylated nitrilebutadiene rubber (XNBR) and carboxylated styrene-butadiene rubber (XSBR) were prepared by combining gamma irradiation vulcanization with spray drying technology, which can effectively reduce the particle size of rubber particles. This study has shown that in the irradiation range of $0-250 \mathrm{kGy}$, UFRs with smaller particle size $(2-10 \mu \mathrm{m})$ are obtained due to the simultaneous mainchain scission and crosslinking of rubber macromolecules at the higher dose of the gamma ray. The UFXNBR filled poly (BAa) obtains a maximum impact strength of about $18 \mathrm{~kJ} \cdot \mathrm{m}^{-2}$ when gamma irradiated vulcanization at $200 \mathrm{kGy}, \mathrm{T}_{\mathrm{g}}$ of the composite reaches to $173{ }^{\circ} \mathrm{C}$ by addition of UFXNBR irradiated at $250 \mathrm{kGy}$, and the thermal and mechanical properties of the system are improved simultaneously. UFRs prepared by the gamma ray crosslinking-spray drying method can be used as an effective toughening filler for polybenzoxazine.

\subsubsection{Inorganic particles modified polybenzoxazine}

Inorganic particles have the properties of high strength, high hardness, high temperature and corrosion resistance. ${ }^{[43]}$ Therefore, the thermal and mechanical properties, dielectric properties, flame retardancy and optical properties of the composites can be improved simultaneously by blending inorganic particles with thermoset resins. And, the final properties are closely related to the type, morphology, size, and content of particles. Commonly used inorganic particle fillers include transition metal compounds. ${ }^{[4]} \quad \mathrm{SiO}_{2},{ }^{[45]}$ $\mathrm{CaCO}_{3},{ }^{[46]}$ and $\mathrm{ZrO}_{2},{ }^{[47]}$ and et. al.
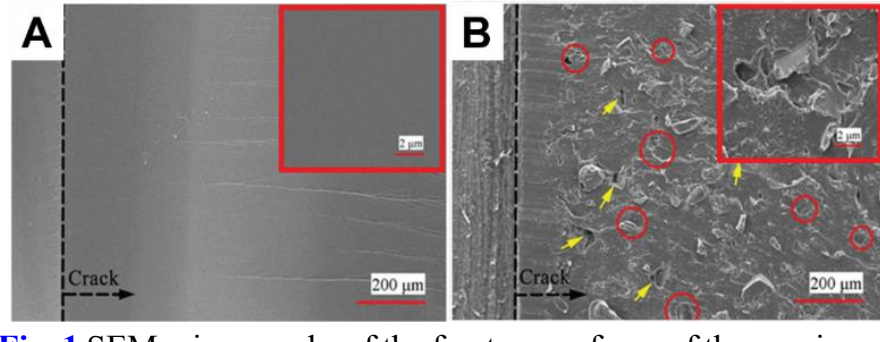

Fig. 1 SEM micrographs of the fracture surfaces of the specimens after the single-edge-notch 3-point bend (SEN-3PB) tests. (A) Pristine PBA-a, (B) PBA-a /PA12/OMMT-2\%.

Zhou et al..$^{[48]}$ used polyamide 12 (PA12) and modified montmorillonite (OMMT) to toughen benzoxazine resin. A series of PBA-a/PA12/OMMT composites with different contents of OMMT particles were prepared and characterized. When the OMMT content increases to $1 \mathrm{wt} \%$, the fracture toughness $\left(\mathrm{K}_{\mathrm{IC}}\right)$ and fracture energy $\left(\mathrm{G}_{\mathrm{IC}}\right)$ of PBA$\mathrm{a} / \mathrm{PA} 12 / \mathrm{OMMT}$ composites reaches $1.36 \mathrm{MPa} \cdot \mathrm{m}^{1 / 2}$ and 315.76 $\mathrm{J} \cdot \mathrm{m}^{-2}$, which are $67.9 \%$ and $181.4 \%$ higher than the original PBA-a. The scanning electron microscope (SEM) results show that the PBA-a/PA12/OMMT composite has a toughening mechanism of crack deflection, PA12 and OMMT clay particles cause large voids and debonding as shown in Fig. 1. Meanwhile, the storage modulus and $\mathrm{T}_{\mathrm{g}}$ of PBAa/PA12/OMMT composites gradually increase from $4.54 \mathrm{GPa}$, $222{ }^{\circ} \mathrm{C}$ for PBA-a/PA12/OMMT ( $1 \mathrm{wt} \%$ OMMT) to $5.34 \mathrm{GPa}$, 
$230{ }^{\circ} \mathrm{C}$ for PBA-a/PA12/OMMT ( $2 \mathrm{wt} \%$ OMMT).

Liu et al..$^{[49]}$ prepared silicon nitride (SN) nanoparticle reinforced benzoxazine nanocomposites. The strong interaction between the nanofiller and the polymer matrix makes the SN nanoparticles disperse in the PBA-a uniformly, which is conducive to stress transfer and distribution from the matrix to filler. At the maximum SN nanoparticle content (30 $\mathrm{wt} \%$ ), the dynamic thermomechanical analysis (DMA) results show that the initial storage modulus and $\mathrm{T}_{\mathrm{g}}$ of the nanocomposites are $2 \mathrm{GPa}$ and $47{ }^{\circ} \mathrm{C}$ higher than that of the unmodified PBA-a, respectively. The tensile strength and modulus are significantly improved from $3.1 \mathrm{GPa}$ and $29 \mathrm{MPa}$ for the PBA-a to 3.8 GPa and $53 \mathrm{MPa}$ for SN nanoparticle (30 $\mathrm{wt} \%$ ) reinforced benzoxazine. The addition of nano-SN significantly improves the stiffness and thermal properties of the composite, but the elongation at break values for all the nanocomposite decrease due to the higher rigidity of ceramic fillers.

With the improvement of environmental awareness, natural fillers reinforced polymer composites have become a very attractive research field in recent years. Natural hermit crab shell (CSP) is mainly composed of calcium carbonate $\left(\mathrm{CaCO}_{3}\right)$ and chitin biopolymer. A polybenzoxazine blending system modified by crab shell particles was prepared. ${ }^{[46]}$ The existence of a chitin biopolymer in CSP can slightly catalyze the benzoxazine ring-opening and the high content of $\mathrm{CaCO}_{3}$ can increase the $\mathrm{T}_{\mathrm{g}}$ of the cured blend. Furthermore, the excellent interaction between $\mathrm{CaCO}_{3}$ particles and matrix makes the storage modulus of the composites increase with the CSP content increasing. The $\mathrm{T}_{\mathrm{g}}$ and storage modulus of PBAa/CSP-30 wt $\%$ reach $209^{\circ} \mathrm{C}$ and $4.51 \mathrm{GPa}$ compared to $167^{\circ} \mathrm{C}$ and $1.91 \mathrm{GPa}$ for pristine PBA-a. To further improve the performances in CSP particles/benzoxazine system, a higher content of CSP is often required. Lately, Liu et al. proposed a new environment-friendly and economical toughening method. ${ }^{[50]}$ The researchers blended catechin-rich micro size acacia catechu (AC) particles with BA-a. The DSC results show that AC particles have a positive effect on the curing process, which attributes to the catalytic effect of $-\mathrm{OH}$ in tannic acid. When the content of AC particles is only $4 \mathrm{wt} \%$, the blended system forms a macroscopic phase separation structure, and the impact strength reaches $5.7 \pm 0.21 \mathrm{~kJ} \cdot \mathrm{m}^{-2}$ which is $301.7 \%$ higher than that of unmodified PBA-a. At the same time, the thermomechanical properties, tensile properties and thermal properties are also improved. In the recent report of their team, silane modified acacia catechu particles (MACPs) also have a remarkable reinforce effect on dicyanate ester of bisphenol-A/bisphenol-A based benzoxazine (DCBA/BA-a) blend composites. ${ }^{\left[{ }^{[1]}\right.}$ he polar groups grafted on the surface of acacia catechu particles can interact with hydroxyl groups of the blended resin, resulting in good interfacial adhesion and dispersion between MACPs and polymer matrix.

To improve the toughness of the resin, a concept of building an "organic-inorganic" interpenetrating network structure between mesoporous particles and benzoxazines was proposed. ${ }^{[52]}$ This method has been widely used in the field of superhydrophobic coatings to improve the wear resistance of the coating. ${ }^{[53,54]}$ Initially, mesoporous $\mathrm{SiO}_{2}$ (SBA-15) is chosen to toughen and modify benzoxazine, creating a superhydrophobic polymer surface with high abrasion resistance. The results show that the water contact angles (WCAs) are almost unchanged after $400 \mathrm{~cm}$ at $1.6 \mathrm{kPa}$ of abrasion for BA-a/SBA-15, while for BA-a/nano $\mathrm{SiO}_{2}$, the WCAs decreased sharply after $80 \mathrm{~cm}$ of abrasion. The following research shows ${ }^{[5]}$ imidazole can further improve the mechanical properties and chemical resistance of BA-a/SBA15 by adjusting the processing method to form a multi-scale micro- and nano-structures (inorganic-organic interpenetrating structures, self-similar sacrificial structures and micro-nano structures). Lately, polyurethane (PU ${ }^{[56]}$ and flexible aliphatic epoxy (EP) ${ }^{[57]}$ are introduced into our system. PU/BA-a/SBA-15 film not only has mechanical robust, flexible, and thermal stability but also exhibits excellent recycle usage and anti-corrosion property. Meanwhile, EP/BA-a/SBA-15 superhydrophobic surfaces could resist an abrasion distance of more than $2.9 \mathrm{~m}$ under $1.6 \mathrm{kPa}$, which can clarify the outstanding toughness of the blend system. The concept of "organic-inorganic" interpenetrating network structure based tough method has a broad application, for example, mesoporous $\mathrm{TiO}_{2}$ particles have a similar effect on fabricating tough and robustness films with reversible surface properties. ${ }^{[1,58]}$

\subsection{Reaction induce phase separation method-based modification}

\subsubsection{Thermoplastics modified polybenzoxazine}

Blending with the high glass transition temperature $\left(\mathrm{T}_{\mathrm{g}}\right)$ and high modulus thermoplastic engineering plastics (TP) (including Polysulfone (PSF), ${ }^{[59]}$ polyetherimide (PEI), ${ }^{[60]}$ polyethersulfone (PES), ${ }^{[61]}$ polyether ketone (PEK) ${ }^{[62]}$ etc) is also a common method for toughening and modification of thermoset resins (TS). The mechanism of TP toughening TS is currently recognized mainly as crack pinning, crack path deflection, particle-yield induced shear bands and microcracks. ${ }^{[63]}$ Controlling the phase morphology of the cured product is the core content to realize toughing in TP/TS blends By changing the composition, ratio and curing process of the modifier to regulate the kinetic and thermodynamic factors can control the phase separation process and obtain phase separated structure, such as dispersed phase, bi-continuous phase and phase inversion structure. And the formation of a bi-continuous phase is often accompanied by the best toughening effect. The disadvantage of this method is that the thermoplastic resin has a high molecular weight and cannot be dissolved in common solvents easily, which will deteriorate the processing of blends.

Poly (aryl ether nitrile) (PEN) is a type of highperformance engineering plastics with semi-crystalline, high toughness and excellent thermo-mechanical properties. 
However, due to its semi-crystalline nature, its solubility in common organic solvents is poor, which hinders the physical blending of PEN with TS. ${ }^{[64]}$ Zong et al. ${ }^{[65]}$ synthesized phthalazinone-bearing copoly (biphenyl ether nitrile) (PPBEN) through the solution polycondensation of 4-(4Hydroxyphenyl)-2,3-naphthyridin-1-one

(DHPZ), biphenyldiol with 2,6-difluorobenzonitrile. The improved impact strength of PBOZ was obtained by blending with PPBEN significantly. When the content of PPBEN is $10 \mathrm{phr}$, the impact strength of PPBEN/PBOZ increases by $202 \%$ compared with that of unmodified PBOZ. At the same time, the PPBEN/PBOZ blends maintain the original thermal properties with $\mathrm{T}_{\mathrm{g}}$ at approximately $210^{\circ} \mathrm{C}$. The SEM results show that PPBEN is dispersed in the system with sea-island structure, which prone to cause crack deflection and disproportionation thereby terminating the external stress, as seen in Fig. 2.

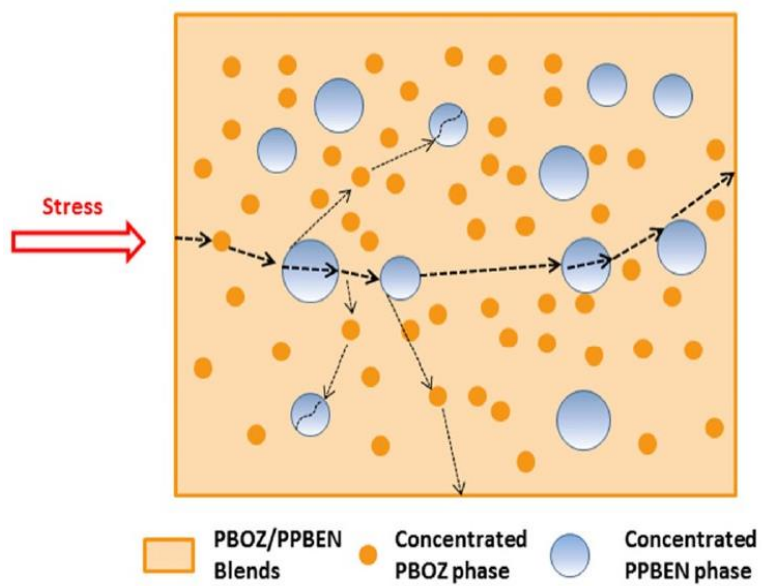

Fig. 2 Illustration of the mechanism of PBOZ toughened by PPBEN, reproduced with the permissison from [65]. Copyright@John Wiley and Sons.

Some early reports ${ }^{[66]}$ have shown that ternary blends, TS/TP/TP systems, exhibit better mechanical properties than TS/TP binary blends due to their more complex phase structure. Xia et al. ${ }^{[22]}$ prepared sulfonated polysulfone/polysulfone/benzoxazine (SPSU/PSU/PBZ-m) ternary blends. The results show that SPSU can effectively reduce the curing temperature of benzoxazine because of the existence of sulfonic acid $\left(-\mathrm{SO}_{3} \mathrm{H}\right)$ thus affecting the phase separation process and final phase structure. The toughness of SPSU/PSU/PBZ-m blends is improved greatly than that of PBZ-m and PSU/PBZ-m binary blends. Compared with PBZ$\mathrm{m}(41.9 \mathrm{MPa}$ and $1.58 \%)$, the tensile strength and elongation at break of SPSU/PSU/PBZ-3/27/70 are $110.6 \mathrm{MPa}$ and $6.78 \%$, respectively. This is due to two different multiphase structures obtained in the blend of SPSU/PSU/PBZ-3/27/70. One is coreshell particles of SPSU/PBZ-m and bi-continuous structure of
PSU/PBZ-m, the other is core-shell particles of SPSU/PBZ-m and inverse structure of PSU/PBZ-m. The phase evolution of SPSU/PSU/PBZ-m blends can be illustrated as in Fig. 3.

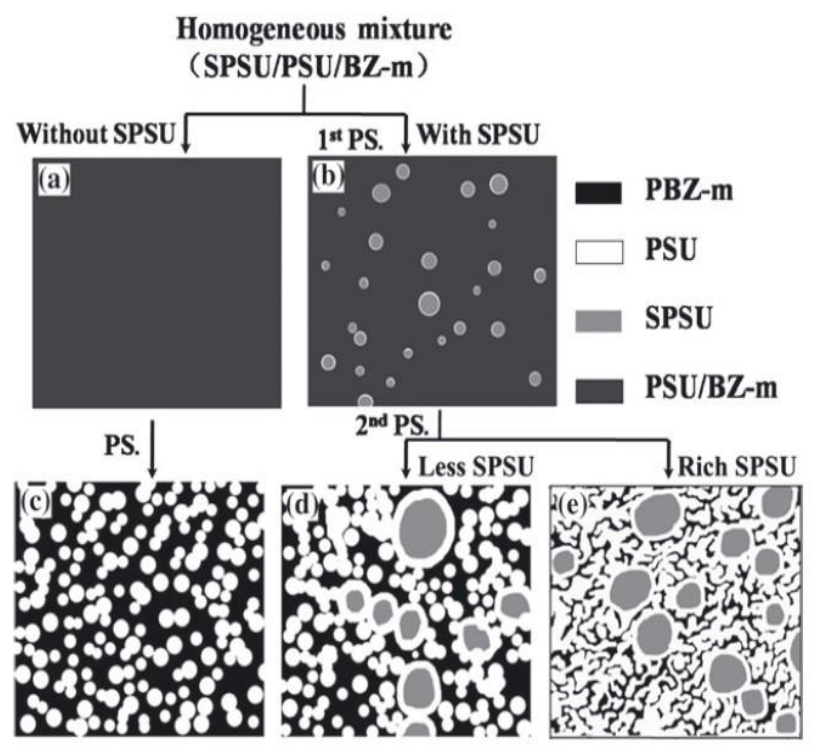

Fig. 3 The evolution of phase structures for SPSU/PSU/PBZ-m blends with different ratios of SPSU/PSU, reproduced with the permission from [22]. Copyright@John Wiley and Sons.

Besides, different from other TS/TP resin blends, ${ }^{[67,68]}$ benzoxazine generates a large number of phenolic hydroxyl groups in the ring-opening and curing process, which can form intermolecular hydrogen bonds with polar groups (such as carboxyl, hydroxyl, carbonyl, ether bonds, etc.) in polycaprolactone $\quad(\mathrm{PCL}),{ }^{[69]}$ polycarbonate $(\mathrm{PC}),{ }^{[70]}$ polyoxyethylene (PEO), ${ }^{[71]}$ etc. In the early stage of the curing, the intermolecular hydrogen bonds increase the miscibility of the blended system. Then, the intermolecular hydrogen bond becomes weaken at high temperatures, and the system occurs phase separation driven by entropy.

Tiptipakorn et al. ${ }^{[72]}$ studied the properties of the blends of benzoxazine and polycaprolactone (PCL). Two $\mathrm{T}_{\mathrm{gS}}$ can be observed in DMA curves, which illustrates a phase-separated structure formed within the range of PCL content studied. Furthermore, a synergistic behavior between PCL and PBA-a is also found. The $\mathrm{T}_{\mathrm{g}}$ for PBA-a and PCL are $169{ }^{\circ} \mathrm{C}$ and nearly $250{ }^{\circ} \mathrm{C}$, respectively, while the maximum $\mathrm{T}_{\mathrm{g}}$ value of the blend system is $281{ }^{\circ} \mathrm{C}$. With the increase of PCL content and molecular weight, the modulus and hardness of the blends decrease, but the elongation at break and the area under the stress-strain curve increase, which illustrates the toughness of PBA-a is improved. When the PCL molecular weight and content reaches $10 \mathrm{~K}$ and $10 \mathrm{wt} \%$, the area under the stressstrain curve of blends increases to $137.9 \mathrm{MPa}$, which is $328 \%$ higher than that of pristine PBA-a. 


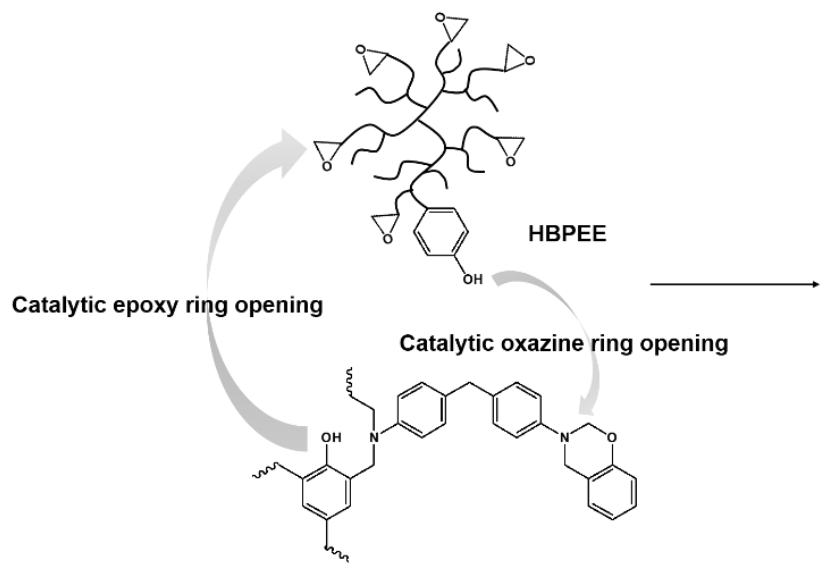

$\mathrm{BOZ}$

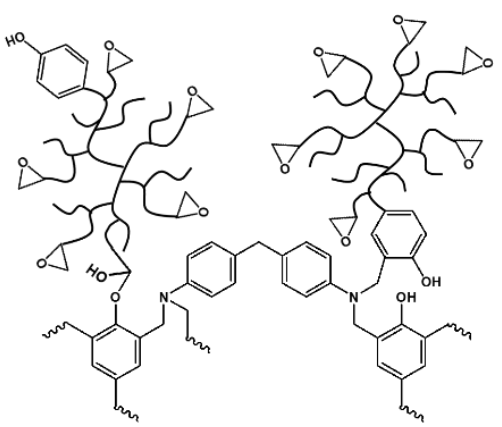

Cured blends

Scheme 4 The catalytic reactions between HBPEE and BOZ.

Koschek et al. ${ }^{[69]}$ added PCL with BA-a covalently and non-covalently to obtain copolymerized and blended PCL/BA-a systems, respectively. Tosylated PCL-(OTs) reduced the polymerization temperature of benzoxazine and covalently combined with benzoxazine network. Thus, a homogeneous phase structure and transparent appearance are showed. On the contrary, for hydroxyl-terminated PCL$(\mathrm{OH})_{2} / \mathrm{BA}-\mathrm{a}$ blends, benzoxazine requires a higher temperature for curing. As the PCL content increases, there is more and more non covalently bonded PCL in the polymer network, which leads to the blend polymer with a heterogeneous phase structure. The tensile test showed that covalently incorporated PCL could toughen the brittle benzoxazine, the tensile strength increased to $93 \mathrm{MPa}$ for 20 $\mathrm{wt} \%$ PCL-(OTs) $2 / \mathrm{BA}-\mathrm{a}$, and the elongation at break increased to $3.1 \%$, while that of pure PBA-a was $65 \mathrm{MPa}$ and $1.3 \%$. However, the young's modulus of all samples decreased due to the introduction of soft thermoplastic.

\subsubsection{Thermoset resin modified polybenzoxazine}

As stated above, TP can sacrifice the processability of thermosetting resin because of its high molecular weight and poor solubility in the common solvent. Innovatively, introducing reactive TS into thermoset resin as the second component to form a phase-separated structure based on the principle of reaction induced phase separation is developed very recently. The results show that TS/TS blends achieved the balance of thermal and processing properties while toughening.

Cyanate ester (CE) modified benzoxazine has attracted more and more attention due to the low dielectric loss, good flame retardancy and thermal properties of CE ${ }^{[73]}$ However, a micro-scale phase separation structure is difficult to obtain in this system because the copolymerization of two components always leads to the formation of a triazine ring cross-linked network. Li et al. ${ }^{[74]}$ successfully prepared novel cardanolbased benzoxazine (C-BOZ)/bisphenol A cyanate ester (BADCy) blends with a sea-island phase separation structure. The thermodynamic difference between $\mathrm{C}-\mathrm{BOZ}$ and BADCy is enhanced by the introduction of long-chain alkyl in the benzene ring, but the degree of phase separation decreases with the increase of BADCy content. When the weight ratio reaches $5 / 5$, the phase separation cannot be carried out due to the high viscosity of the blend.

Zhao et al. ${ }^{[75]}$ prepared a novel benzoxazine (BOZ)/epoxy resin (ER)/imidazole (MZ) blend with a sea-island microphase structure. Due to the selective catalysis of imidazole, ER polymerizes preferentially. ER and $\mathrm{BOZ}$ form a dispersed phase and a continuous phase, respectively. Compared with homogeneous PBOZ and PBOZ/ER blends, the toughness and thermal properties of the phase-separated blend system are greatly improved. Among them, the impact strength of the $\mathrm{PBOZ} / \mathrm{ER} / \mathrm{MZ}$ system reaches $33.8 \mathrm{~kJ} \cdot \mathrm{m}^{-2}$, which is near twice as much as that of the $\mathrm{PBOZ}$ system. The $\mathrm{T}_{\mathrm{g}}$ increases from $212.4{ }^{\circ} \mathrm{C}$ for $\mathrm{PBOZ}$ to $228.9^{\circ} \mathrm{C}$ for blends.

The final phase-separated morphology of the blend system has an important influence on the mechanical properties of the system. How to control the phase structure to improve the performance has also received widespread attention. Wang et al. used N, N'-(2,2,4-trimethylhexane-1,6-diyl) bismaleimide (TBMI) and imidazole as raw materials to tough polybenzoxazine. The effects of initial curing temperature and modifier concentration on the final phase-separated morphology were studied respectively. ${ }^{[21,76,77]}$ The BA-a/TBMI blend with a bi-continuous phase structure was prepared successfully. Compared with PBA-a and PTBMI, the impact strength of the cured BT11 (weight ratio of BA-a to TBMI is $1: 1)$ without imidazole increases by $78.8 \%$ and $137 \%$. Furthermore, the impact strength of imidazole-containing cured BTI113 (imidazole content is $3 \mathrm{wt} \%$ ) is $15 \%$ higher than that of BT11, reaching $20.3 \mathrm{~kJ} \cdot \mathrm{m}^{-2}$. Wang et al. ${ }^{[78]}$ further studied the molecular structure influence on phase-separated structures. The results show that the phase separation of phenol-4,4'-diaminodiphenyl methane based benzoxazine ( $\mathrm{P}$ $\mathrm{ddm}) / \mathrm{TBMI} /$ imidazole blend is easier than that of BAa/TBMI/imidazole, which caused by the different FloryHuggins parameters and viscosity of different molecular. 
Table 2. Details of hyperbranched polymer modified polybenzoxazine.

\begin{tabular}{|c|c|c|c|c|c|}
\hline Modifier & $\begin{array}{c}\text { Impact strength } \\
\left(\mathrm{kJ} \cdot \mathrm{m}^{-2}\right)\end{array}$ & $\begin{array}{l}\text { Flexural strength } \\
(\mathrm{MPa})\end{array}$ & $\begin{array}{c}\text { Tensile strength } \\
(\mathrm{MPa})\end{array}$ & $\operatorname{Tg}\left({ }^{\circ} \mathrm{C}\right)$ & Ref. \\
\hline $\begin{array}{l}\text { HBPEE- } 2 \\
(5 \mathrm{wt} \%)\end{array}$ & $\begin{array}{c}210 \% \uparrow \\
(5 \text { to } 15.5)\end{array}$ & $\begin{array}{c}8 \% \uparrow \\
(125 \text { to } 135)\end{array}$ & I & $\begin{array}{c}6 \% \uparrow \\
\text { (5.1 to } 5.4)\end{array}$ & [82] \\
\hline $\begin{array}{c}\text { GO-HE } \\
(0.05 \mathrm{wt} \%)\end{array}$ & $\begin{array}{c}139 \% \uparrow \\
\text { (7.36 to } 17.6)\end{array}$ & $\begin{array}{c}14 \% \uparrow \\
(125 \text { to } 143)\end{array}$ & l & $\begin{array}{c}12{ }^{\circ} \mathrm{C} \uparrow \\
(211 \text { to } 223)\end{array}$ & [83] \\
\hline $\begin{array}{c}\text { HBP- } \\
\text { AMIM }^{+} \text {PF6- }^{-} \\
(3 \mathrm{wt} \%)\end{array}$ & $\begin{array}{c}80.4 \% \uparrow \\
(8.1 \text { to } 14.6)\end{array}$ & $\begin{array}{c}57.8 \% \uparrow \\
\text { (61.5 to } 97)\end{array}$ & $\begin{array}{c}76.6 \% \uparrow \\
(32.7 \text { to } 57.7)\end{array}$ & $\begin{array}{c}16^{\circ} \mathrm{C} \uparrow \\
\text { (232 to } 248 \text { ) }\end{array}$ & [84] \\
\hline $\begin{array}{c}\text { HBP- } \\
\text { AOIM }^{+} \mathrm{PF}^{-}\end{array}$ & $\begin{array}{c}143 \% \uparrow \\
(8.0 \text { to } 19.5)\end{array}$ & $\begin{array}{c}55 \% \uparrow \\
(61.5 \text { to } 95.5)\end{array}$ & $\begin{array}{c}37 \% \uparrow \\
(32.5 \text { to } 44.5)\end{array}$ & $\begin{array}{c}12{ }^{\circ} \mathrm{C} \downarrow \\
(215 \text { to } 193)\end{array}$ & [85] \\
\hline
\end{tabular}

\subsection{Reactive functional groups-based modification}

3.3.1 Hyperbranched polymer modified polybenzoxazine Hyperbranched polymers (HBPs) are a new type of polymer material. ${ }^{[79]}$ It is a series of similar compounds with increasing molecular weight obtained by gradually controlling the repeated reaction with small molecules as the growth point. ${ }^{[80,81]}$ HBPs have extended dendritic structures, which determine their high steric hindrance, less chain entanglement and small intermolecular interaction force, therefore, the viscosity of HBPs is relatively low. The synthesis process of HBPs is simple and the size of the molecular particle is adjustable, and the functional spherical shell can assemble functional groups as required. ${ }^{[80]}$ In this way, the structure and phase state of the modified cured product can be effectively controlled, which provides a great possibility for the modification of benzoxazine. Furthermore, it can also introduce a variety of active end groups into the molecular chain to improve its reaction with benzoxazine. In summary, HBPs toughened benzoxazine has the following advantages: 1) avoiding sacrificing the thermal stability and modulus of the cured resin; 2) having excellent processing performance; 3 ) HBPs have good compatibility with benzoxazine because of their spherical three-dimensional structures; 4) the active end groups of HBPS can directly react with benzoxazine to form a three-dimensional network structure to improve the interface between HBPs and polybenzoxazine.

A novel hyperbranched polyether epoxy resin (HBPEE) with stiff fluorene units and flexible aliphatic chains was used as a toughening agent for benzoxazine resin (BOZ). ${ }^{[82]}$ The content of HBPEE and molecular weight on the performance of the mixed system was studied. The results show that when HBPEE has a medium molecular weight Mn ( 3900), the blend system shows the best comprehensive properties. When its content is $5 \mathrm{wt} \%$, the impact strength increases by $210 \%$ compared to that of the unmodified polybenzoxazine, while maintaining the simultaneous increase in flexural modulus and flexural strength. After curing, a homogeneous structure is observed in all blends. This is caused by the interaction between HBPEE and BOZ (Scheme 4). The simultaneous improvement in these properties can be attributed to the reaction between HBPEE and the phenolic hydroxyl group generated after the ring-opening of benzoxazine, which destroyed the hydrogen bonding network of benzoxazine, thereby increasing the crosslink density. At the same time, the hyperbranched structure can provide more free volume (molecular cavity), which is conducive to the dispersion and transfer of impact energy. The rheological behavior of the uncured blend shows that HBPEE has little effect on the

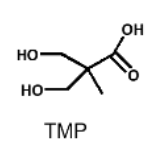

$+$

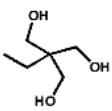

DMPA

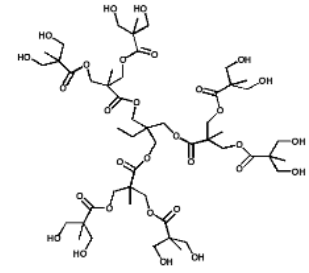

HBP-2

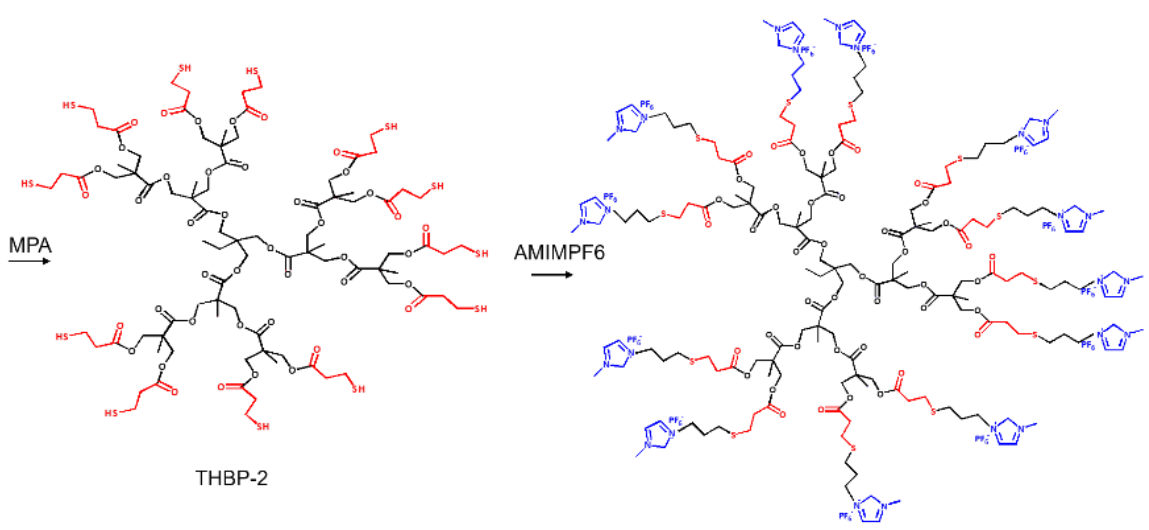

HBP-AMIM+PF6--2

Scheme 5 Synthesis of hyperbranched polyester ionic liquids. 


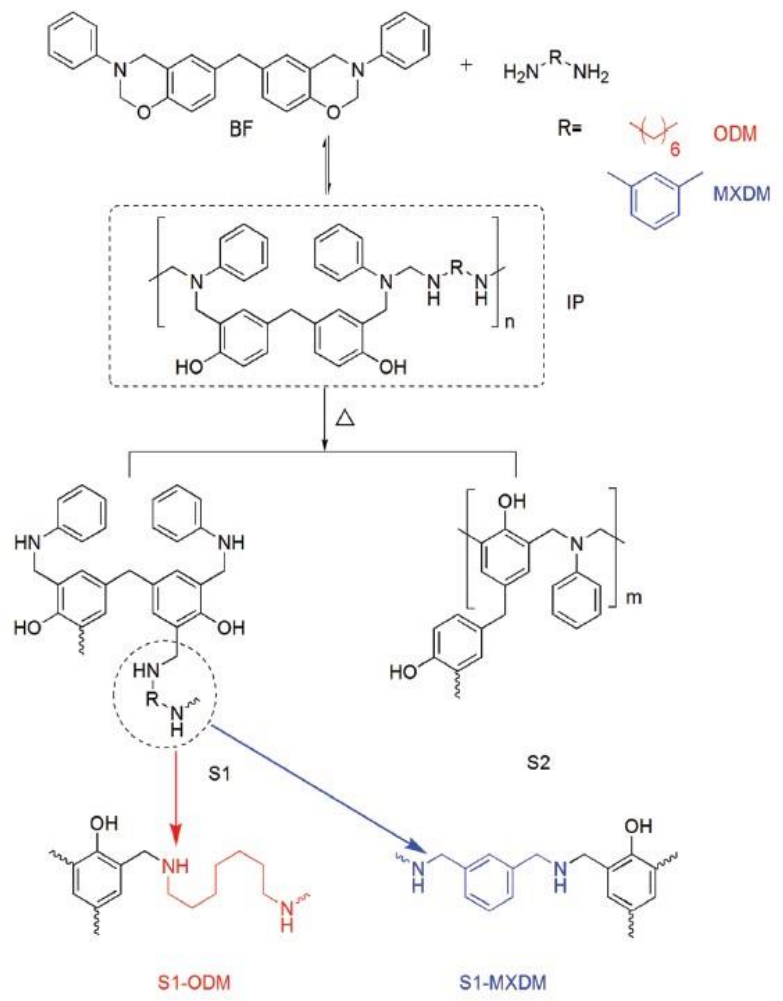

Scheme 6 Phase separation mechanism of BF/amine systems, reproduced with the permission from [86]. Copyright@ John Wiley and Sons.

processing performance of $\mathrm{BOZ}$ due to its inherent low viscosity characteristics. However, the thermal performance of the system has decreased $\left(\mathrm{T}_{\mathrm{g}}\right.$ has decreased from $212{ }^{\circ} \mathrm{C}$ to $201{ }^{\circ} \mathrm{C}$ ). In a recent report, ${ }^{[83]} \mathrm{HBPEE}$ grafted graphene oxide (GO-HE) and benzoxazine resin blends were designed with ameliorated dispersion/shedding and interface interaction between GO-HE and BOZ. In this system, thermogravimetric and thermal stability is significantly improved. The impact strength and flexural strength are increased by $139 \%$ and $14.4 \%$ compared to that of unmodified $\mathrm{PBOZ}$, respectively, and $\mathrm{T}_{\mathrm{g}}$ is also increased by $12{ }^{\circ} \mathrm{C}$, which reaches a balance of comprehensive performances (Table 2).

Hyperbranched polymer ionic liquids have attracted much attention due to their higher miscibility and reactivity. Zhang et al. ${ }^{[84]}$ synthesized a new type of hyperbranched polymer ionic liquid using thiol-ended hyperbranched polyester (THBP) and 1-allyl-3-methylimidazole hexafluorophosphate $\left(\mathrm{AMIM}^{+} \mathrm{PF}^{-}\right)$by thiol-ene click reaction. The synthetic route of ionic liquid HBP-AMIM+PF6- is shown in Scheme 5. HBP$\mathrm{AMIM}^{+} \mathrm{PF}^{-}$can effectively reduce the benzoxazine curing temperature and form a homogeneous structure. When the content reaches $3 \mathrm{wt} \%$, the tensile strength, toughness, flexural strength, flexural modulus and impact strength of blend are increased by about $76.6 \%, 279.3 \%, 57.8 \%, 22.3 \%$ and $80.4 \%$, respectively. Furthermore, synthesized hyperbranched polymer ionic liquids with different alkyl chain length (HBP$\mathrm{AMIM}^{+} \mathrm{PF}^{-}, \mathrm{HBP}^{-} \mathrm{ABIM}^{+} \mathrm{PF}^{-}, \mathrm{HBP}^{-\mathrm{AHIM}^{+} \mathrm{PF}^{-} \text {and HBP- }}$
$\left.\mathrm{AOIM}^{+} \mathrm{PF}^{-}\right),{ }^{[85]}$ were also used to modify the benzoxazine/epoxy thermosets (BA/ECC). With the increasing alkyl chain length of hyperbranched polymeric ionic liquids, the phase morphology of blends changes from homogeneous to sea-island structure, which further improved the toughness of the blends. Meanwhile, the blend of $\mathrm{BOZ}$ and $\mathrm{HBP}^{-A O I M}{ }^{+} \mathrm{PF}^{-}$- (the longest alkyl chain) exhibits the best impact properties and tensile toughness. But, due to the long alkyl chain, the crosslinking density decreases, which leads to the thermal stability decreases slightly and the detail data are showed in Table 2.

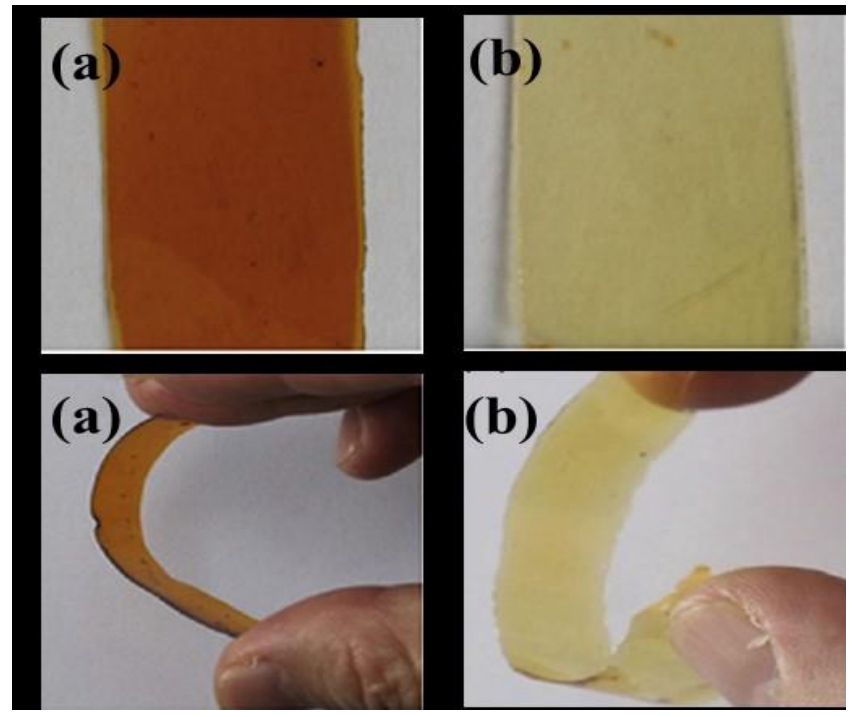

Fig. 4 Polybenzoxazine films (a) bisphenol-A-melamine benzoxazine and (b) phenol-melamine benzoxazine, reproduced with the permission from.

\subsubsection{Other small molecular/polymer modified polybenzoxazine}

Another strategy to get a balance between processing and tough properties is blending small molecular substances with TS. Linear octanediamine (ODM) and $m$-xylylenediamine containing aromatic rings (MXDM) were copolymerized with bisphenol-F-based benzoxazine monomer (BF). ${ }^{[86]}$ The toughness of the system is significantly improved, especially when the BF/ODM/MXDM molar ratio is 1:0.5:0.5, the elongation at break reaches $10.55 \%$ and the breaking strength is $82.67 \mathrm{MPa}$, which is $86 \%$ and $128 \%$ higher than that of pristine polybenzoxazine, respectively. However, the thermomechanical performance of the system has a decline. By adjusting the content of the flexible amine in the benzoxazine/amine blend system, the degree of phase separation induced by the amine/benzoxazine copolymerization can be controlled to realize the toughening polybenzoxazine. The phase separation mechanism of the amine/benzoxazine is shown in Scheme 6, where the oxazine ring of benzoxazine reacts with amine through typical nucleophilic substitution to form an intermediate polymer. The linear intermediate polymer decomposes into two new molecular structures by heating, resulting in phase separation. 

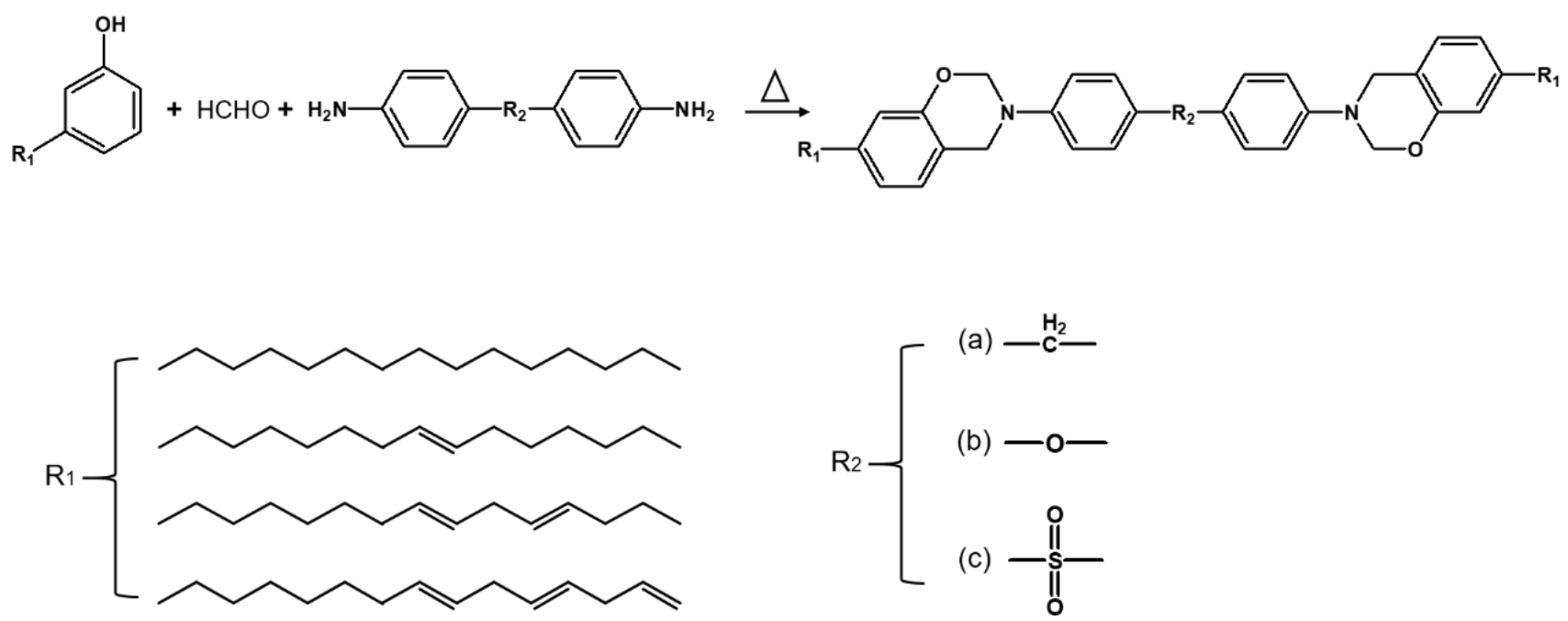

Scheme 7 Synthesis of cardanol-based aromatic diamine benzoxazine.

On the other hand, considering the existence of many kinds of hydrogen bonds that inhibit the high degree polymerization of benzoxazine and lead to the brittleness of the final product [16], the idea of adding small molecules hydrogen bond donor or acceptor to adjust the hydrogen bond structure of benzoxazine to achieve toughening effect has been favored by researchers. ${ }^{[87,88]}$ Luan et al. ${ }^{[89]}$ introduced 4,4-bipyridine (Bpy) as a hydrogen bond acceptor into benzoxazine and increased the performance of polybenzoxazine by increasing the crosslink density. The optimal performance can be obtained when the molar ratio of BA-a to Bpy is 1:0.5 (PBAaB-0.5), the tensile strength increases from $32.5 \mathrm{MPa}$ for PBA-a to $43 \mathrm{MPa}$ for PBAaB- 0.5 , the elongation at break reaches $2.04 \%$, but $\mathrm{T}_{\mathrm{g}}$ decreases from $206{ }^{\circ} \mathrm{C}$ to $178{ }^{\circ} \mathrm{C}$. The method of regulating the hydrogen bond of the system by introducing small molecules into the system can achieve the toughening purpose, but the toughening effective is negligible with a negative effect on the thermal performance of the system.

In our group, ${ }^{[90]}$ a polymer poly(ether-thiourea) containing nonlinear hydrogen bonds (Zigzag arrays) named TUEG 3 was introduced into benzoxazine, as a hydrogen bond acceptor. $\mathrm{TUEG}_{3}$ can form an intermolecular hydrogen bond with the phenolic hydroxyl group in benzoxazine, which can re-adjust the type and number of hydrogen bonds in the system and improve the crosslink density. The TUEG $3 / \mathrm{BA}_{3}$-a blend system possesses a homogeneous structure due to the unique hydrogen bond structure of $\mathrm{TUEG}_{3}$, and outstanding comprehensive performance can be easily got. The impact strength of polybenzoxazine improves from $6.03 \mathrm{~kJ} \cdot \mathrm{m}^{-2}$ for pure polybenzoxazine to the highest value $15.45 \mathrm{~kJ} \cdot \mathrm{m}^{-2}$ for polybenzoxazine blended with $5 \mathrm{wt} \% \mathrm{TUEG}_{3}$, meanwhile, the corresponding flexural strength is changing from $103.8 \mathrm{MPa}$ to $140.2 \mathrm{MPa}$ and $\mathrm{T}_{\mathrm{g}}$ is increasing from $192{ }^{\circ} \mathrm{C}$ to $206^{\circ} \mathrm{C}$. The enhanced comprehensive properties of benzoxazine resin are achieved by the introduction of the unique hydrogen bond structure. Introducing a polymer to modulate the hydrogen bonds in blend proposed a new idea for toughening benzoxazine resin.

\subsection{Molecular design-based modification}

Synthesizing new benzoxazine monomers (small molecule benzoxazines) by changing the phenol and amine source is a widely used modification method. Melamine is an inexpensive, non-toxic, stable, and commercially available substance and benzoxazines based on melamine can readily be synthesized in the solvent of water and methanol. Liu et al. ${ }^{[23]}$ chose melamine as the amine source and synthesized a low-viscosity benzoxazine, which can easily be made into transparent films without bubbles and cracks under solvent-free conditions as shown in Fig. 4. Compared with traditional benzoxazines, the toughness is significantly improved.

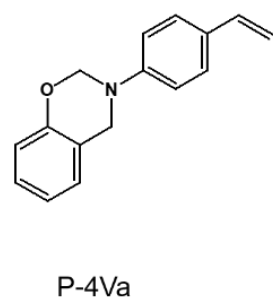

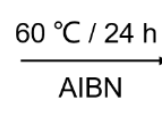

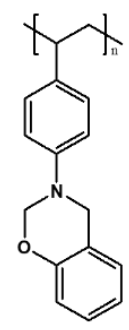

Oligo(P-4Va)
Scheme 8 Radical polymerization of P-4va.

Cardanol is a natural phenolic compound obtained by vacuum distillation of renewable natural resource cashew nutshell liquid and has been widely used in the synthesis of benzoxazine monomers and improves the toughness of the blends. Unfortunately, because of the monofunctional structure of cardanol-based benzoxazine, the thermal properties of the blends are usually reduced. Gu et al. ${ }^{[24]}$ synthesized a series of cardanol-based aromatic diamine benzoxazine (BZ-Xc) monomers using cardanol, formaldehyde and aromatic diamines with different bridging groups - $\mathrm{CH}_{2}-,-\mathrm{O}-,-\mathrm{SO}_{2}$ - as shown in Scheme 7, named BZMc, BZ-Oc, BZ-Sc, respectively. It is added as a plasticizer and a diluent to 4, 4' -diamino diphenylmethane (DDM)-based bisbenzoxazine (BM). The flexibility of the alkyl side chain can significantly reduce the melt viscosity of the BM/BZ-Xc 
and improve the toughness of the copolymer. When the addition amount of BZ-Xc is $10 \%$, the impact strength of the $\mathrm{BM} / \mathrm{BZ}-\mathrm{Mc}$, BM/BZ-Oc, BM/BZ-Sc system reaches 31.8, 30.9 , and $30.1 \mathrm{~J} \cdot \mathrm{m}^{-2}$ respectively, which is significantly improved compared with $17.3 \mathrm{~J} \cdot \mathrm{m}^{-2}$ of pristine poly $(\mathrm{BM})$. However, the $\mathrm{T}_{\mathrm{g}}$ of the copolymers decreases with the increasing contents of BZ-Xc because of the reduced crosslink density and the molecular structure regularity by the introduction of the alkyl side group.

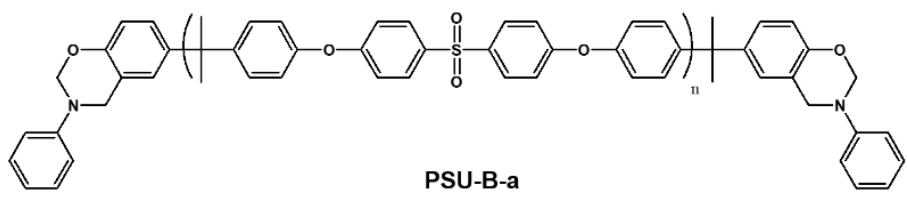

Scheme 9 Chemical structure of PSU-B-a.

Main-chain type benzoxazine polymers are a kind of polymeric precursor that consists of repeating benzoxazine units in their main chain. ${ }^{[25]}$ Compared with small molecule benzoxazine which using benzoxazine monomer as the polymerization precursor, the main-chain benzoxazine reduces the suspended chain end units and increases crosslink density, thereby improving their thermal, dielectric and mechanical properties. Han et al. ${ }^{[27]}$ synthesized two novel main-chain type benzoxazines from daidzein, aromatic/aliphatic diamine, and paraformaldehyde. Daidzein compound possesses two phenolic hydroxyls and a benzopyrone structure which can improve the thermalmechanical properties of thermosets thereby making it an appropriate phenolic resource. The benzoxazine synthesized in this work combines the advantages of the main-chain benzoxazine and the daidzein-based polymer shows surprising thermal stability with a $\mathrm{T}_{\mathrm{g}}$ more than $400{ }^{\circ} \mathrm{C}$. However, the mechanical properties are not reported in the article.

Takeichi et al..$^{[31]}$ used 2, 2'-azobisisobutyronitrile as a radical initiator to synthesize a benzoxazine (oligo (P-4va)) as shown in Scheme 8. The linear polymers with benzoxazine side chains are further synthesized by copolymerization oligo (P-4va) with methyl methacrylate (MMA) and n-butyl acrylate (BuA). The cured film from oligo (P-4va)/BuA copolymers exhibited significantly improved flexibility and the toughness, which indicates that the synthesized copolymers containing pendent BZs can serve as high-performance PBZs.

Telechelic benzoxazine refers to a polymer precursor with benzoxazine end groups. Yagci et al. ${ }^{[32]}$ synthesized a novel class of thermally cross-linkable oligomers (PSU-B-a) consisting of polysulfone structure as a backbone with benzoxazine functional groups connected to both ends (Scheme 9). The toughness of the resin can be notably improved by copolymerizing it with BA-a. The elongation at break and toughness of PSU-B-a-4/10 wt $\%$ BA-a are increased to $195 \%$ and $113 \mathrm{kPa}$, and the unmodified PBA-a is only $37 \%$ and $11 \mathrm{kPa}$. In recent work, ${ }^{\left[{ }^{[1]}\right.}$ the thermal stability of benzoxazine-terminated polysulfone has also been verified, which depends on the concentration of benzoxazine monomer and the chain length of the polysulfone chain.

\section{Conclusion}

polybenzoxazine has excellent mechanical properties, low cost and wide application prospect, but the shortcomings, such as high brittleness and low impact resistance, greatly limit the application of polybenzoxazine in high-performance fields such as machinery, electronics and aerospace. In recent years, researches on benzoxazine have continued to increase, and the performance improvement of polybenzoxazine has made breakthroughs. The existed toughening methods can improve the toughness of polybenzoxazine effectively, but it is still a challenge to achieve a balance between the toughness, thermal stability and processing properties. Therefore, the future direction of the research and development of polybenzoxazine toughening modification should be to find new toughening methods to improve the comprehensive performance of polybenzoxazines and make them more widely used in different areas.

\section{Acknowledgments}

Financial support was provided by the National Natural Science Foundation of China (Project Nos. 51773185, U1810118, and 51503187), the Key Research and Development Plan of Shanxi Province (Project No. 201803D421088), the Program for the Innovative Talents of Higher Learning Institutions of Shanxi and The North University of China Fund for Distinguished Young Scholars (Project No. JQ201903)

\section{Supporting information}

Not applicable

\section{Conflict of interest}

The authors have no conflicts of interest to declare.

\section{References}

[1] W. Hu, J. Huang, X. Zhang, S. Zhao, L. Pei, H. Li, Y. Liu and Z. Wang, Prog. Org. Coat., 2020, 147, 105771, doi: 10.1016/j.porgcoat.2020.105771.

[2] B. G. Sun, K. X. Yang, Q. Lei, H. Q. Shi, Y. Q. Li, N. Hu and S. Y. Fu, Compos. Part A-Appl. S., 2018, 112, 11-17, doi: 10.1016/j.compositesa.2018.05.021.

[3] Y. Wang, H. Niu, Q. Lu, W. Zhang, X. Qiao, H. Niu, Y. Zhang and W. Wang, Spectrochim. Acta A, 2020, 225, 117524, doi: 10.1016/j.saa.2019.117524

[4] H. Yan, C. Sun, Z. Fang, X. Liu, J. Zhu and H. Wang, Polymer, 2016, 97, 418-427, doi: 10.1016/j.polymer.2016.05.053.

[5] C. Yang, W. Shi, X. Chen, K. Zhang, X. Zhou, X. Sun, S. Ding, S. Liu and Z. Xie, Dyes Pigments, 2020, 176, 108206, doi: 10.1016/j.dyepig.2020.108206.

[6] H. Zhu, W. Hu, S. Zhao, X. Zhang, L. Pei, G. Zhao and Z. Wang, J. Mater. Sci., 2019, 55, 2215-2225, doi: 10.1007/s10853019-04050-1. 
[7] I. Dueramae, C. Jubsilp, T. Takeichi and S. Rimdusit, J. Therm. Anal. Calorim., 2013, 116, 435-446, doi: 10.1007/s10973-0133542-0.

[8] H. Ishida and D. J. Allen, J. Polym. Sci. Pol. Phys., 1996, 34, 1019-1030, doi: 10.1002/(SICI)10990488(19960430)34:6<1019::AID-POLB1>3.0.CO;2-T.

[9] H. Ishida, and H. Y. Low, Macromolecules, 1997, 30, 1099 1106, doi: 10.1021/ma960539a

[10] Q. C. Ran, D. X. Zhang, R. Q. Zhu and Y. Gu, Polymer, 2012, 53, 4119-4127, doi: 10.1016/j.polymer.2012.07.033

[11] P. Yang and Y. Gu, J. Appl. Polym. Sci., 2012, 124, 24152422, doi: 10.1002/app.35305.

[12] H. Y. Low and H. Ishida, Polym. Degrad. Stabil., 2006, 91, 805-815, doi: 10.1016/j.polymdegradstab.2005.05.030.

[13] T. Agag and T. Takeichi, High Perform. Polym., 2001, 13, S327-S342, doi: 10.1088/0954-0083/13/2/328.

[14] J. Si, P. Xu, W. He, S. Wang and X. Jing, Compos. Part AAppl. S., 2012, 43, 2249-2255, doi: 10.1016/j.compositesa.2012.07.025.

[15] R. Ganfoud, N. Guigo, L. Puchot, P. Verge and N. Sbirrazzuoli, Eur. Polym. J., 2019, 119, 120-129, doi: 10.1016/j.eurpolymj.2019.07.026.

[16] Y. Bai, P. Yang, Y. Song, R. Zhu and Y. Gu, RSC Adv., 2016, 6, 45630-45635, doi: 10.1039/C6RA08881C .

[17] J. Jang and D. Seo, Appl. Polym. Sci., 1998, 67, 1-10, doi: 10.1002/(SICI)1097-4628(19980103)67:1<1::AID-

APP1>3.0.CO;2-V.

[18] B. B. Johnsen, A. J. Kinloch, R. D. Mohammed, A. C. Taylor and S. Sprenger, Polymer, 2007, 48, 530-541, doi: 10.1016/j.polymer.2006.11.038.

[19] X. Zhang, W. Xu, X. Xia, Z. Zhang and R. Yu, Mater. Lett., 2006, 60, 3319-3323, doi: 10.1016/j.matlet.2006.04.023.

[20] H. Ardhyananta, T. Kawauchi, T. Takeichi and H. Ismail, High Perform. Polym., 2010, 22, 609-632, doi: 10.1177/0954008309354129.

[21] Z. Wang, Q. Ran, R. Zhu and Y. Gu, RSC Adv., 2013, 3, 13501353, doi: 10.1007/s12274-016-1357-6.

[22] Y. Xia, P. Yang, Y. Miao, C. Zhang and Y. Gu, Polym. Int., 2015, 64, 118-125, doi: 10.1002/pi.4766.

[23] J. Shi, X. Zheng, L. Xie, F. Cao, Y. Wu and W. Liu, Eur. Polym. J., 2013, 49, 4054-4061, doi: 10.1016/j.eurpolymj.2013.09.011.

[24] C. Zhang, Y. Zhang, Q. Zhou, H. Ling and Y. Gu, J. Polym. Eng., 2014, 34, 561-568, doi: 10.1515/polyeng-2014-0018

[25] A. Chernykh, J. Liu and H. Ishida, Polymer, 2006, 47, 76647669, doi: 10.1016/j.polymer.2006.08.041.

[26] J. Dai, N. Teng, Y. Peng, Y. Liu, L. Cao, J. Zhu and X. Liu, ChemSusChem, 2018, 11, 3175-3183, doi: 10.1002/cssc.201801404.
[27] M. Han, S. You, Y. Wang, K. Zhang and S. Yang, Polymers, 2019, 11, 1341, doi: 10.3390/polym11081341.

[28] B. Kiskan, B. Aydogan and Y. Yagci, J. Polym. Sci. Pol. Chem., 2009, 47, 804-811, doi: 1002/pola.23197.

[29] J. Q. Zhao, Y. Liu, S. M. Zhang, J. J. Qiu and C. M. Liu, React. Funct. Polym., 2020, 149, 104516, doi: 10.1016/j.reactfunctpolym.2020.104516.

[30] H. Oie, A. Sudo and T. Endo, J. Polym. Sci. Pol. Chem., 2013, 51, 2035-2039, doi: 10.1002/pola.26590.

[31] T. Takeichi, S. Thongpradith and T. Kawauchi, Molecules, 2015, 20, 6488-503, doi: 10.3390/molecules20046488.

[32] S. Ates, C. Dizman, B. Aydogan, B. Kiskan, L. Torun and Y. Yagci, Polymer, 2011, 52, 1504-1509, doi: 10.1016/j.polymer.2011.01.051.

[33] T. Orhan, S. Ates, J. Hacaloglu and Y. Yagci, J. Anal. Appl. Pyrol., 2012, 94, 146-152, doi: 10.1016/j.jaap.2011.12.001.

[34] S. Ren, X. Miao and W. Song, Polym. J., 2018, 51, 397-403, doi: 10.1038/s41428-018-0155-2.

[35] C. Kaynak and O. Cagatay, Polym. Test, 2006, 25, 296-305 doi: 10.1016/j.polymertesting.2006.01.004.

[36] S. Grishchuk, L. Sorochynska, O. C. Vorster and J. KargerKocsis, J. Appl. Polym. Sci., 2013, 127, 5082-5093 doi: 10.1002/app.38123.

[37] J. Jang and H. Yang, Compos. Sci. Technol., 2000, 60, $457-$ 463, doi: 10.1016/S0266-3538(99)00146-3.

[38] O. Gryshchuk, N. Jost and K. Kocsis, Polymer, 2002, 43, 4763-4768, doi: 10.1016/S0032-3861(02)00314-2.

[39] S. Chen, Q. Wang and T. Wang, Polym. Test, 2011, 30, 726731, doi: 10.1016/j.polymertesting.2011.06.011.

[40] D. N. Suwitaningsih, S. Katsuta, T. Kawauchi, N. Furukawa and T. Takeichi, J Photopolym. Sci. Tec., 2015, 28, 137-143, doi: 10.2494/photopolymer.28.137.

[41] E. Douse, S. Kopsidas, D. Jesson and I. Hamerton, React. Funct. Polym., 2016, 103, 117-130, doi 10.1016/j.reactfunctpolym.2016.04.009.

[42] R. Taewattana, C. Jubsilp, P. Suwanmala and S. Rimdusit, Radiat. Phys. Chem., 2018, 145, 184-192, doi: 10.1016/j.radphyschem.2018.02.002.

[43] B.B. Johnsen, A.J. Kinloch, R.D. Mohammed, A.C. Taylor and S. Sprenger, Polymer, 2007, 48, 530-541, doi: 10.1016/j.polymer.2006.11.038.

[44] X. Zhang, W. Hu, L. Pei, S. Zhao, C. Zhang and Z. Wang, High Perform. Polym., 2020, 32, 702-709, doi : 10.1177/0954008319899128.

[45] C. Peng, J. Li, Z. Li, Z. Wu and D. Zhou, Mater. Design, 2016, 111, 453-462, doi: 10.1016/j.matdes.2016.08.095.

[46] N. Ramdani, J. Wang, X. Y. He, T. T. Feng, X. D. Xu, W. B. Liu and X. S. Zheng, Mater. Design, 2014, 61, 1-7, doi: 10.1016/j.matdes.2014.04.058. 
[47] Y. Wu, H. Jin, S. Hou and M. Zeng, Wear, 2013, 297, $1025-$ 1031, doi: 10.1016/j.wear.2012.11.047.

[48] J. Zhou, R. Wang, X. He, C. Zhao, H. Gou and L. Zhao, J. Polym. Eng., 2018, 38, 933-943, doi: 10.1515/polyeng-20180020.

[49] N. Ramdani, J. Wang, H. Wang, T. T. Feng, M. Derradji, W. B. Liu, Compos. Sci. Technol., 2014, 105, 73-79, doi: 10.1016/j.compscitech.2014.10.006.

[50] A. Q. Dayo, R. K. Ma, S. Kiran, A. Zegaoui, W. A. Cai, A. H. Shah, J. Wang, M. Derradji and W. B. Liu, Compos. Part AAppl. S., 2018, 105, 258-264, doi 10.1016/j.compositesa.2017.12.004.

[51] A. Zegaoui, M. Derradji, A. Medjahed, A. Q. Dayo, J. Wang, W. A. Cai, W. B. Liu, React. Funct. Polym., 2018, 131, 333-341, doi: 0.1016/j.reactfunctpolym.2018.08.017.

[52] Z. Wang, H. Zhu, N. Cao, R. Du, Y. Liu and G. Zhao, Mater. Lett., 2017, 186, 274-278, doi; 10.1016/j.matlet.2016.10.010.

[53] K. M. Jeong, S. S. Park, S. Nagappan, G. Min, Y. Zhang, M. Qu, Y. Zhang and C. S. Ha, Prog. Org. Coat., 2019, 134, 323-332, doi; 10.1016/j.porgcoat.2019.05.029.

[54] C.E. Corcione, R. Striani and M. Frigione. Prog. Org. Coat., 2014, 77, 803-812, doi: 10.1016/j.porgcoat.2014.01.008.

[55] H. Zhu, W. Hu, Y. Xu, B. Wang, D. Zheng, Y. Fu, C. Zhang, G. Zhao and Z. Wang, Appl. Surf. Sci., 2019, 463, 427-434, doi: 10.1016/j.apsusc.2018.08.241.

[56] H. Zhu, W. Hu, S. Zhao, X. Zhang, L. Pei, G. Zhao, and Z. Wang. Polym. Int., 2020, 55, 2215-2225, doi: 10.1007/s10853019-04050-1.

[57] X. Li, S. Zhao, W. Hu, X. Zhang, L. Pei, Z. Wang, Appl. Surf. Sci., 2019, 481, 374-378, doi: 10.1016/j.apsusc.2019.03.114.

[58] W. Hu, J. Huang, X. Zhang, S. Zhao, L. Pei, C. Zhang, Y. Liu and Z. Wang, Appl. Surf. Sci., 2020, 507, 145168, doi : 10.1016/j.apsusc.2019.145168.

[59] N. Zheng, Y. Huang, H. Y. Liu, J. Gao and Y. W. Mai, Compos. Sci. Technol., 2017, 140, 8-15, doi: 10.1016/j.compscitech.2016.12.017.

[60] L. Ma, L. Meng, G. Wu, Y. Wang, M. Zhao, C. Zhang and Y. Huang, Compos. Sci. Technol., 2015, 117, 289-297, doi: 10.1016/j.compscitech.2015.06.018.

[61] S. E. Lee, E. Jeong, M. Y. Lee, M. K. Lee and Y. S. Lee, J. Ind. Eng. Chem., 2016, 33, 73-79, doi: 10.1016/j.jiec.2015.09.022.

[62] A. M. Díez-Pascual, M. Naffakh, C. Marco, G. Ellis and M. A. Gómez-Fatou, Prog. Mater. Sci., 2012, 57, 1106-1190, doi: 10.1016/j.pmatsci.2012.03.003.

[63] I. Hamerton, L.T. McNamara, B. J. Howlin, P. A. Smith, P. Cross and S. Ward, Macromolecules, 2014, 47, 1946-1958, doi: 10.1021/ma5002436.

[64] X. Wan, Y. Zhan, Z. Long, G. Zeng, Y. Ren and Y. He, Appl.
Surf. Sci., 2017, 425, 905-914, doi: 10.1016/j.apsusc.2017.07.136 [65] L. Zong, J. Li, C. Liu, Y. Zu, N. Li, J. Wang and X. Jian, J. Appl. Polym. Sci., 2019, 137, 48508, doi: 10.1002/app.48508.

[66] G. Pena, A. Eceiza, A. Valea, P. Remiro, P. Oyanguren and I. Mondragon, Polym. Int., 2010, 52, 1444-1453, doi: 10.1002/pi.1209.

[67] Z. Sun, L. Xu, Z. Chen, Y. https://doi.org/10.1002/pi.1209 Tusiime, C. Cheng, S. Zhou, Y Liu, M. Yu and H. Zhang, Polymers, 2019, 11, 461, doi: 3390/polym11030461.

[68] Y. Rosetti, P. Alcouffe, J. P. Pascault, J. F. Gérard and F. Lortie, Materials, 2018, 11, 1960, doi: 10.3390/ma11101960.

[69] H. Schäfer and K. Koschek, Eur. Polym. J., 2018, 108, 582590, doi: 10.1016/j.eurpolymj.2018.09.036.

[70] H. Ishida and Y. H. Lee, J. Appl. Polym. Sci., 2002, 83, 18481855, doi: 10.1002/app.2311.

[71] W. C. Su, F. C. Tsai, C. F. Huang, L. Dai and S. W. Kuo, Polymers, 2019, 11, 201, doi: 10.3390/polym11020201.

[72] S. Tiptipakorn, N. Keungputpong, S. Phothiphiphit and S. Rimdusit, J. Appl. Polym. Sci., 2015, 132, 41915, doi: 10.1002/app.41915.

[73] G. Wu, K. Kou, L. Zhuo, Y. Wang and J. Zhang, Thermochim. Acta, 2013, 559, 86-91, doi: 10.1016/j.tca.2013.02.030.

[74] X. Li, X. Luo and Y. Gu, Phys. Chem. Chem. Phys., 2015, 17, 19255-19260, doi: 10.1039/C5CP02426A.

[75] P. Zhao, Q. Zhou, Y. Deng, R. Zhu and Y. Gu, RSC Adv., 2014, 4, 238-242, doi: 10.1039/C3RA44738C.

[76] Z. Wang, Q. Ran, R. Zhu and Y. Gu, Phys. Chem. Chem. Phys., 2014, 16, 5326-32, doi: 10.1039/C3CP54960G.

[77] Z. Wang, Z. Zhang, Q. Ran, R. Zhu and Y. Gu, RSC Adv., 2013, 3, 14029-14036, doi: 10.1039/C3RA40868J.

[78] Z. Wang, L. Li, Y. Fu, Y. Miao and Y. Gu, Mater. Design, 2016, 107, 230-237, doi: 10.1016/j.matdes.2016.06.046.

[79] L. G. Moradi, M.G. Sari and B. Ramezanzadeh, Prog. Org. Coat., 2020, 142, 105573, doi: 10.1016/j.porgcoat.2020.105573.

[80] M. Flores, X. Fernández-Francos, F. Ferrando, X. Ramis and À. Serra, Polymer, 2012, 53, 5232-5241, doi: 1016/j.polymer.2012.09.031.

[81] R. J. Varley and W. Tian, Polym. Int., 2004, 53, 69-77, doi: $10.1002 /$ pi.1324.

[82] X. Wang, L. Zong, J. Han, J. Wang, C. Liu and X. Jian, Polymer, 2017, 121, 217-227, doi: 10.1016/j.polymer.2017.05.069.

[83] X. Wang, N. Li, J. Wang, G. Li, L. Zong, C. Liu and X. Jian, Compos. Sci. Technol., 2018, 155, 11-21, doi: 10.1016/j.compscitech.2017.11.013.

[84] S. Chen, J. Zhang, J. Zhou, D. Zhang and A. Zhang, Chem. Eng. J., 2018, 334, 1371-1382, doi: 10.1016/j.cej.2017.11.104.

[85] J. Zhang, X. Mi, S. Chen, Z. Xu and D. Zhang, J. Mol. Liq., 2019, 291, 111251, doi: 10.1016/j.molliq.2019.111251. 
[86] Y. Zhao, Y. Xu, Q. Xu, F. Fu, Y. Zhang, T. Endo and X. Liu, Macromol. Chem. Phys., 2018, 219, 1700517, doi: 10.1002/macp. 201700517.

[87] B. Wang, P. Yang, Y. Li, Y. He, R. Zhu, and Y. Gu, Polym. Int., 2017, 66, 1159-1163, doi: 10.1002/pi.5370.

[88] D. Hu and S. Zheng, Polymer, 2010, 51, 6346-6354, doi: 10.1016/j.polymer.2010.10.047.

[89] X. Luan, B. Wang, P. Yang and Y. Gu, J. Polym. Res., 2019, 26, 85, doi: 10.1007/s10965-019-1741-5.

[90] S. Zhao, L. Pei, H. Li, X. Zhang, W. Hu, G. Zhao and Z. Publisher's Note: Engineered Science Publisher remains Wang, Polymer, 2020, 201, 122647, doi: 10.1016/j.polymer.2020.122647.

[91] T. Orhan, S. Ates, J. Hacaloglu and Y. Yagci, J. Anal. Appl. Pyrolysis, 2012, 94, 146-152, doi: 10.1016/j.jaap.2011.12.001.

\section{Author information}

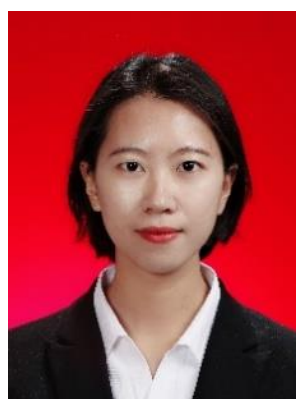

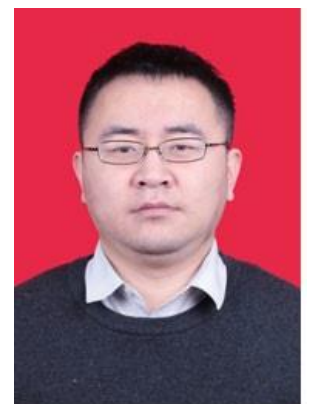

Zhi Wang received his Ph.D. degrees in Materials Science from Sichuan University in 2013. He is currently the professor of the North University of China. His current research interest includes synthesis, modification of thermosetting resins and the preparation of composite materials.
Sipei Zhao received her B.S. degree from North China University in 2014, and now she is studying for the master's degree at North China University. Her current research interest is toughening modification of thermosetting resin. 